Eur J Clin Chem Clin Biochem

1995; 33:479-485

(C) 1995 Walter de Gruyter \& Co.

Berlin - New York

\title{
Simultaneous Assessment of Bone Collagen Synthesis and Degradation in Patients with Different Malignant Tumours Comparison with the Results of ${ }^{99 \mathrm{~m}} \mathrm{Tc}-$ Methylene Bisphosphonate Bone Scintigraphy
} \author{
Hans Wilhelm Mueller-Gaertner ${ }^{2}$ and Hans Reinauer ${ }^{1}$ \\ 1 Institut für Klinische Chemie und Laboratoriumsdiagnostik \\ 2 Abteilung für Nuklearmedizin \\ Heinrich-Heine-Universität Düsseldorf, Düsseldorf, Germany
}

By Wolfgang Withold ${ }^{1}$, Georghe Georgescu ${ }^{2}$, Hassan Khakzad ${ }^{1}$, Henning Vosberg ${ }^{2}$,

(Received February 18/May 20, 1995)

Summary: We report on the diagnostic validity of the serum concentrations of the C-terminal propeptide of type I procollagen (a marker of bone formation) and of the urinary excretion of deoxypyridinoline (a marker of bone resorption) in a consecutive series of 89 tumour patients who were routinely examined by ${ }^{99 \mathrm{~m}} \mathrm{Tc}$-methylene bisphosphonate bone scintigraphy for detection of bone metastases.

$\mathrm{Z}$ score analysis reveals that the discriminating power of deoxypyridinoline is superior to that of calcium excretion whereas the discriminating power of the C-terminal propeptide concentrations is inferior to that of bone alkaline phosphatase values. Accuracy (as assessed by the area under the receiver-operating characteristic curve) was 0.75 for deoxypyridinoline and 0.82 for the C-terminal propeptide. Combination of both markers did not yield an increase of accuracy (0.82) compared with the determination of the C-terminal propeptide concentrations alone. There was a correlation $(r=+0.398 ; p<0.0001)$ between $C$-terminal propeptide concentrations and deoxypyridinoline excretion values in the group of 89 patients examined.

Further studies should be done to elucidate whether the determination of bone collagen turnover is suitable as a screening procedure for detecting bone metastases.

\section{Introduction}

Type I collagen accounts for more than $90 \%$ of the organic matrix of bone and is synthesized in the form of a larger molecule, type I procollagen. This precursor molecule contains additional sequences at both ends which are removed by specific proteinases before the collagen molecules are assembled into fibers. The part removed from the carboxy-terminal end of the molecule enters the circulation where it can be measured by heterogeneous immunoassays (for review see 1.c. (1)). The concentration of this circulating C-terminal propeptide is thought to be directly associated with the number of type I collagen molecules formed. Therefore it can be used to quantify type I collagen synthesis and hence bone formation (2).
Bone collagen is stabilized by the formation of pyridinium cross-links between the terminal, non-helical part of type I collagen molecule and the helical region of another. The cross-links found in bone collagen are formed from two hydroxylysine residues and one lysine residue (= deoxypyridinoline) or from three hydroxylysine residues (= pyridinoline). Deoxypyridinoline is found almost exclusively in bone. The measurement of deoxypyridinoline excretion in urine should therefore specifically reflect the degradation of bone collagen and hence bone resorption (3).

At present only preliminary results are available regarding the clinical significance of markers of bone collagen metabolism in tumour patients (4-6). 
Here we report on the diagnostic validity of the combined assessment of bone collagen synthesis and degradation with respect to detecting bone metastases in patients with different malignant tumours, comparing the results with those of bone scintigraphy. The values of the markers of bone collagen turnover were also compared with those of alkaline phosphatase and urinary calcium excretion which are the presently available measures for routine assessment of bone formation and resorption, respectively.

\section{Materials and Methods}

\section{Characterization of patients by bone scintigraphy}

We examined venous blood specimens and second morning urine samples from a consecutive series of patients ( 34 males, $55 \mathrm{fe}-$ males; range of age: $26-84$ years) with malignant diseases who were routinely examined for the presence of bone metastases/primary bone tumours by ${ }^{99} \mathrm{~m} \mathrm{Tc}$-methylene bisphosphonate bone scintigraphy. Samples were collected between 8:00 and 10:00 a.m.

The diagnoses of the patients were cancers of breast $(n=33)$, bronchia $(n=11)$, prostate $(n=7)$, kidney $(n=4)$, thyroid glands $(n=2)$, oesophagus $(n=2)$, colon $(n=2)$, pharynx $(n=2)$, tongue $(n=2)$, stomach $(n=1)$, tonsils $(n=1)$, uterus $(n=1)$ and parathyroid glands $(n=1)$ as well as malignant melanoma $(n=10)$, lymphoma $(n=5)$, Hodgkins's disease $(n=2)$, multiple myeloma $(\mathrm{n}=1)$, osteosarcoma $(\mathrm{n}=1)$ and Ewing's tumour $(\mathrm{n}=1)$.

In compliance with the results of the scintigraphic examinations (as independently judged by two experienced physicians for nuclear medicine without knowledge of the corresponding biochemical data) the patients were divided into the following groups:

(1) There are no pathological findings (= group $0 ; n=29$ ).

(2) According to the pathological findings (being detectable by scintigraphy) the presence of bone metastases seems to be improbable (= group $1 ; n=33)$, possible (= group $2 ; n=13$ ) and probable ( $=$ group $3 ; n=14)$, respectively.

All procedures involving human subjects were in compliance with the Helsinki Declaration of 1975 (as revised in 1983).

Determination of the carboxy-terminal propeptide of procollagen type $I$ in serum

The concentration of the carboxy-terminal propeptide of procollagen type I was determined by an enzyme immunoassay (ProlagenC $^{\text {TM}}$; Metra Biosystems, Inc., Palo Alto, CA [U.S. A.]). A calibration curve was constructed by a 4-parameter curve fitting algorithm.

The following reference intervals (2.5th-97.5th percentile) for the $\mathrm{C}$-terminal propeptide in serum were established in apparently healthy persons: (1) $50-180 \mu \mathrm{g} / \mathrm{l}$ (males, $\mathrm{n}=51$ ) (2) $50-145 \mu \mathrm{g} / \mathrm{l}$ (females, $n=51$ ). Range of age was $23-58$ years (males) and 23-59 years (females).

Determination of the urinary excretion of deoxypyridinoline

Urinary concentration of deoxypyridinoline was determined by a competitive enzyme immunoassay (Pyrilinks ${ }^{\text {TM }}$-D; Metra Biosystems Inc., Palo Alto, CA [U.S. A.]) employing a monoclonal antibody against deoxypyridinoline. A calibration curve was constructed by employing a 4-parameter curve fitting equation.
Determination of creatinine concentration in urine was performed using the fully mechanized analyzer Hitachi/BM 704 (Boehringer Mannheim $\mathrm{GmbH}$, Mannheim, Germany) by employing a kinetic modification of the Jaffé procedure (7).

Urinary deoxypyridinoline excretion is given as $\mu \mathrm{mol} / \mathrm{mol}$ creatinine.

The following reference interval (2.5th-97.5th percentile) for excretion of deoxypyridinoline in second morning urine samples was established in apparently healthy persoons (urine samples were obtained between 8.00 and 10.00 a.m.): 1.3-9.3 (median: 4.6) $\mu \mathrm{mol} / \mathrm{mol}$ creatinine $(\mathrm{n}=99 ; 51$ males and 48 females; range of age: $19-62$ years). There was no dependence of reference values on $\operatorname{sex}(p>0.1)$.

Measurement of total alkaline phosphatase activity in serum

Activity of total alkaline phosphatase was measured at $+25^{\circ} \mathrm{C}$ by the optimized standard method conforming to the Recommendations of the German Society for Clinical Chemistry (8) using the fully mechanized analyzer Hitachi/BM 704 (Boehringer Mannheim GmbH, Mannheim, Germany).

Determination of bone alkaline phosphatase mass concentration in serum

Bone alkaline phosphatase mass concentration was determined by an immunoradiometric assay (Tandem ${ }^{\circledR}-\mathrm{R}$ Ostase ${ }^{\mathrm{TM}}$; Hybritech Inc., San Diego, CA [U. S. A.]; no. 3040 BE) employing two monoclonal antibodies against two different epitopes of the bone alkaline phosphatase molecule. A calibration curve was constructed by linear interpolation between the plotted analytical results.

The following reference intervals (2.5th-97.5th percentile) for bone alkaline phosphatase concentration in serum were established in apparently healthy persons: (1) $3.8-21.3 \mu \mathrm{g} / \mathrm{l}$ (males, $\mathrm{n}=51$ ) (2) $3.4-15.0 \mu \mathrm{g} / \mathrm{l}$ (females, $\mathrm{n}=51$ ). Range of age was $20-55$ years (males) and 18-56 years (females).

\section{Determination of the urinary excretion of calcium}

Calcium excretion in second morning urine samples (see above) was determined with an EFOX 5053 flame emission spectrometer (Eppendorf Gerätebau Netheler + Hinz GmbH, Hamburg, Germany). Data are given in $\mathrm{mol} / \mathrm{mol}$ creatinine (upper reference limit: $0.6 \mathrm{~mol} / \mathrm{mol}$ )

\section{Statistical analysis}

The statistical methods employed inlcude the U-test according to Wilcoxon, Mann \& Whitney (two-tailed) for unpaired samples, linear regression equations as well as linear correlation coefficients (9). The discriminating power was estimated by calculating the $Z$ scores (for explanations see tab. 1). The accuracy was determined as the area under the receiver-operating characteristic curve.

\section{Results}

Discriminating power of C-terminal

propeptide concentrations and

deoxypyridinoline excretion

in different groups of patients

Figure 1 shows the distributions of C-terminal propeptide concentrations and deoxypyridinoline excretion in 


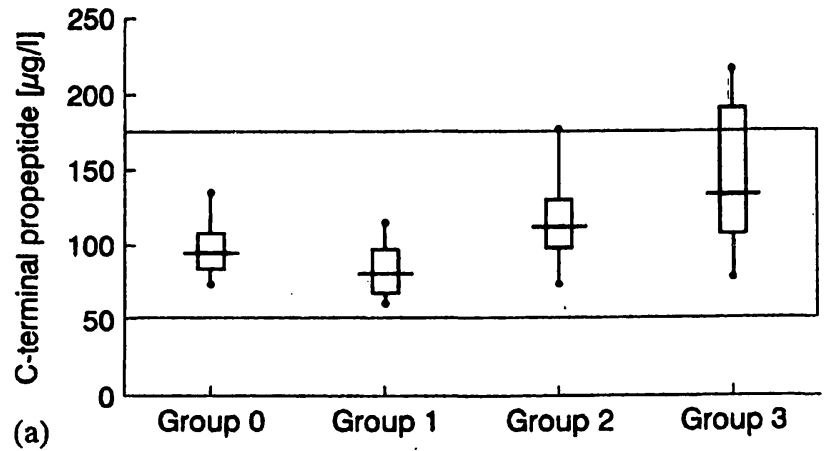

Fig. 1 C-terminal propeptide values (fig. 1a) and deoxypyridinoline excretion (fig. 1b) in different groups of patients (as defined under Materials and Methods).

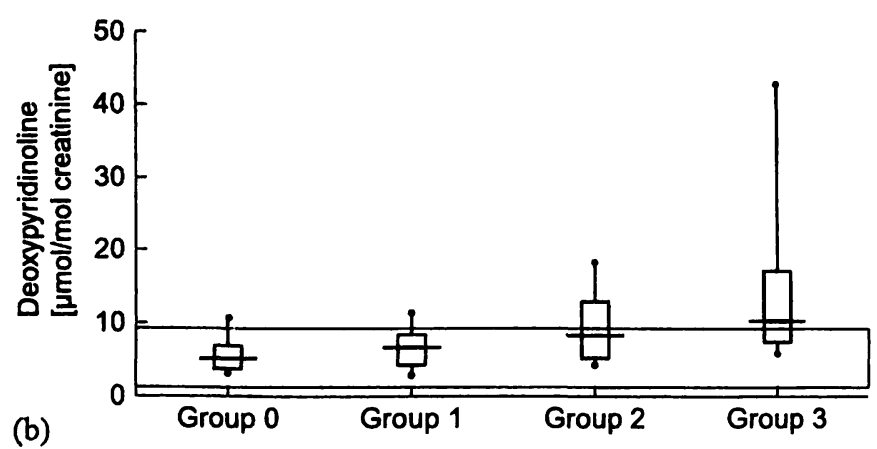

Upper and lower lines indicate the 10th and 90th percentile, boxes the 25 th and 75 th percentile and the line in the box the 50th percentile.

Tab. 1 Discriminating power of biochemical markers of bone metabolism in different patient groups (as described under Materials and Methods).

\begin{tabular}{|c|c|c|c|c|c|}
\hline & \multicolumn{5}{|l|}{ Z score sa $^{a}$} \\
\hline & $\begin{array}{l}\text { C-terminal } \\
\text { propeptide }\end{array}$ & $\begin{array}{l}\text { Deoxypyridinoline } \\
\text { excretion }\end{array}$ & $\begin{array}{l}\text { Bone alkaline } \\
\text { phosphatase }\end{array}$ & $\begin{array}{l}\text { Total alkaline } \\
\text { phosphatase }\end{array}$ & $\begin{array}{l}\text { Calcium } \\
\text { excretion }\end{array}$ \\
\hline & {$[\mu \mathrm{g} / 1]$} & $\begin{array}{l}{[\mu \mathrm{mol} / \mathrm{mol}} \\
\text { creatinine] }\end{array}$ & {$[\mu \mathrm{g} / \mathrm{l}]$} & {$[\mathrm{U} / \mathrm{l}]$} & $\begin{array}{l}\text { [mol } / \mathrm{mol} \\
\text { creatinine] }\end{array}$ \\
\hline $\begin{array}{l}\text { Group } 1 \text { vs group } 0 \\
\text { Group } 2 \text { vs group } 0 \\
\text { Group } 3 \text { vs group } 0\end{array}$ & $\begin{array}{l}-0.76^{* *} \\
+0.85^{*} \\
+2.12^{* * *}\end{array}$ & $\begin{array}{l}+0.25 \\
+1.11^{* *} \\
+2.75^{* * *}\end{array}$ & $\begin{array}{l}+0.43 \\
+2.00^{*} \\
+8.12^{* * *}\end{array}$ & $\begin{array}{l}+0.13 \\
+1.46^{* *} \\
+3.52^{* * *}\end{array}$ & $\begin{array}{l}+0.1 \\
-0.4 \\
-0.6\end{array}$ \\
\hline
\end{tabular}

a $Z$ score $=\left(\right.$ mean $\left._{\text {group } X}-\operatorname{mean}_{\text {group } 0}\right) / \mathrm{SD}_{\text {group } 0}(X=1,2,3)$

$* 0.01 \leq \mathrm{p}<0.05$

$* * 0.001 \leq \mathrm{p}<0.01$

$* * * \mathrm{p}<0.001$

the four groups of patients (as defined under Materials and Methods). $Z$ score analysis reveals that the discriminating power of deoxypyridinoline is superior to that of calcium excretion whereas C-terminal propeptide concentrations are inferior to bone as well as total alkaline phosphatase values if groups 1,2 and 3, respectively, are compared with group 0 (tab. 1). Four patients belonging to group 0 showed an increased urinary excretion of deoxypyridinoline (among them a patient with a carcinoma of the parathyroid glands). There was no significant difference in the $\gamma$-glutamyl transferase activity concentrations in the four groups of patients $(p>0.05)$.

\section{Relationship between the examined biochemical markers of bone metabolism}

There was a correlation $(r=+0.398 ; \mathrm{p}<0.0001)$ between C-terminal propeptide concentrations and deoxypyridinoline excretion values in the group of 89 patients examined. The same applies to the relationship between $\mathrm{C}$-terminal propeptide values and bone alkaline phosphatase concentrations $(p<0.0001)$.

Apart from one patient with primary hyperparathyroidism all patients were normocalcaemic. None of the urine samples examined showed a urinary excretion of calcium above the upper reference limit. A lack of correlation was found between calcium excretion and all other markers of bone resorption as well as bone formation (tab. 2).

Only $5(22 \%)$ of 23 patients with excretion values of deoxypyridinoline above the upper reference limit $(9.3$

Tab. 2 Correlation coefficients between C-terminal propeptide concentrations, deoxypyridinoline excretion, bone alkaline phosphatase values and calcium excretion in serum/urine samples from 89 tumour patients with and without bone metastases.

\begin{tabular}{|c|c|}
\hline Analytes & $\begin{array}{l}\text { Correlation } \\
\text { coefficients }\end{array}$ \\
\hline $\begin{array}{l}\text { C-terminal propeptide vs. } \\
\text { deoxypyridinoline excretion }\end{array}$ & $\begin{array}{l}\mathrm{r}=+0.398 \\
\mathrm{p}<0.0001\end{array}$ \\
\hline $\begin{array}{l}\text { C-terminal propeptide vs. } \\
\text { bone alkaline phosphatase }\end{array}$ & $\begin{array}{l}r=+0.529 \\
p<0.0001\end{array}$ \\
\hline $\begin{array}{l}\text { C-terminal propeptide vs. } \\
\text { calcium excretion }\end{array}$ & $\begin{array}{l}r=-0.036 \\
p>0.05\end{array}$ \\
\hline $\begin{array}{l}\text { Bone alkaline phosphatase vs. } \\
\text { deoxypyridinoline excretion }\end{array}$ & $\begin{array}{l}r=+0.726 \\
p<0.0001\end{array}$ \\
\hline $\begin{array}{l}\text { Bone alkaline phosphatase vs. } \\
\text { calcium excretion }\end{array}$ & $\begin{array}{l}r=-0.201 \\
p>0.05\end{array}$ \\
\hline $\begin{array}{l}\text { Deoxypyridinoline vs. } \\
\text { calcium excretion }\end{array}$ & $\begin{array}{l}r=-0.125 \\
p>0.05\end{array}$ \\
\hline
\end{tabular}


$\mu \mathrm{mol} / \mathrm{mol}$ creatinine) showed a concomitant rise of Cterminal propeptide concentrations $(>180 \mu \mathrm{g} / 1$ [males] and $>140 \mu \mathrm{g} / \mathrm{l}$ [females], respectively). For further details see table 3 and figure 2 .

Tab. 3 Comparison between C-terminal propeptide concentrations and urinary excretion of deoxypyridinoline in 89 tumour patients (with and without bone metastases).

\begin{tabular}{llll}
\hline $\begin{array}{l}\text { Number of sera } \\
\text { with C-terminal } \\
\text { propeptide } \\
\text { concentrations }\end{array}$ & $\mathrm{n}$ & \multicolumn{2}{l}{$\begin{array}{l}\text { Number of urines with } \\
\text { deoxypyridinoline } \\
\text { excretion values }\end{array}$} \\
\cline { 2 - 4 } & & $\begin{array}{l}\text { lelow } \\
\text { the upper } \\
\text { reference } \\
\text { limit }^{\mathrm{b}}\end{array}$ & $\begin{array}{l}\text { above } \\
\text { the upper } \\
\text { reference } \\
\text { limit }^{\mathrm{b}}\end{array}$ \\
\hline $\begin{array}{l}\text { below the upper } \\
\text { reference limit }\end{array}$ & $79(89 \%)$ & $61(69 \%)$ & $18(20 \%)$ \\
$\begin{array}{l}\text { above the upper } \\
\text { reference limit }\end{array}$ & $10(11 \%)$ & $5(5 \%)$ & $5(6 \%)$ \\
\hline & $89(100 \%)$ & $66(74 \%)$ & $23(26 \%)$ \\
\hline
\end{tabular}

a $180 \mu \mathrm{g} / \mathrm{\text {[males}}$ ] and $145 \mu \mathrm{g} / \mathrm{l}$ [females], respectively

b deoxypyridinoline $9.3 \mu \mathrm{mol} / \mathrm{mol}$ creatinine

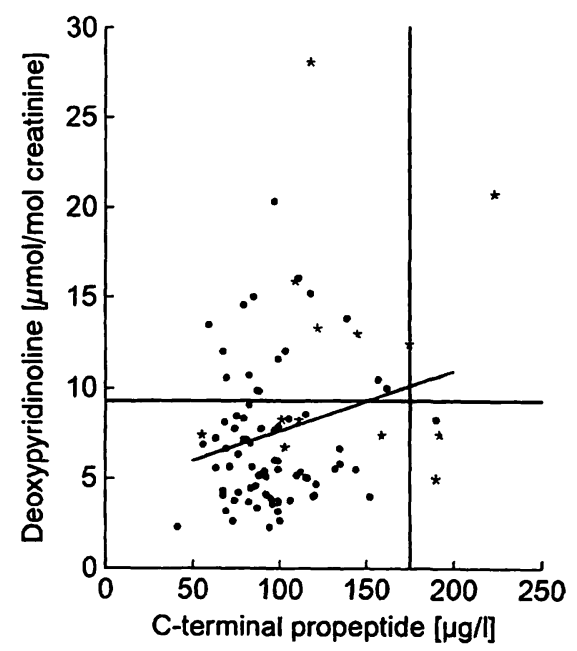

Fig. 2 Comparison between the urinary excretion of deoxypyridinoline and C-terminal propeptide values in samples from $88 \mathrm{pa}-$ tients (with and without bone metastases).

Patients belonging to group 3 are indicated by stars, those belonging to the other three groups by dots (one pair of serum/urine samples with a deoxypyridinoline excretion of $58 \mu \mathrm{mol} / \mathrm{mol}$ creatinine and a C-terminal propeptide value of $210 \mu \mathrm{g} / \mathrm{l}$ is not presented in the diagram). The horizontal and vertical lines, respectively, indicate the upper reference limits (97.5th percentile) of deoxypyridinoline excretion (deoxypyridinoline $9.3 \mu \mathrm{mol} / \mathrm{mol}$ creatinine) and of C-terminal propeptide concentrations $(175 \mu \mathrm{g} / \mathrm{l})$ without taking into consideration the dependence of C-terminal propeptide reference values on sex.

The relationship between the results of the two methods is given by the following regression equation: Deoxypyridinoline excretion $[\mu \mathrm{mol} / \mathrm{mol}$ creatinine $]=4.332+0.033 \times$ C-terminal propeptide concentration $[\mu \mathrm{g} / 1](\mathrm{r}=+0.398 ; \mathrm{p}<0.0001)$.
Receiver-operating characteristic (ROC) plots for C-terminal propeptide concentrations and deoxypyridinoline excretion

To evaluate the efficacy of the bone collagen metabolism markers for discriminating between groups 0 and 1 on the one hand and groups 2 and 3 on the other, threshold values were fixed corresponding to the 10 th, 20 th, ..., 90th percentile of the distribution of C-terminal propeptide concentrations and deoxypyridinoline excretion in the group of 89 patients examined (fig. 3). For the combination of the two markers an increase of at least one marker above the 10th, 20th, ..., 90th percentile (see above) was defined as a positive test result.

The accuracy was 0.82 for C-terminal propeptide values and 0.75 for deoxypyridinoline excretion; a combination of both markers did not further increase the value of accuracy (0.82) compared with the determination of $C$ terminal propeptide concentrations alone.

At a threshold value of $100 \mu \mathrm{g} / \mathrm{l} \mathrm{C}$-terminal propeptide and of $7.7 \mu \mathrm{mol} / \mathrm{mol}$ creatinine for deoxypyridinoline (corresponding to the 60th percentiles; see above) the diagnostic efficiency (= sum of diagnostic sensitivity and diagnostic specificity) for the combination of both

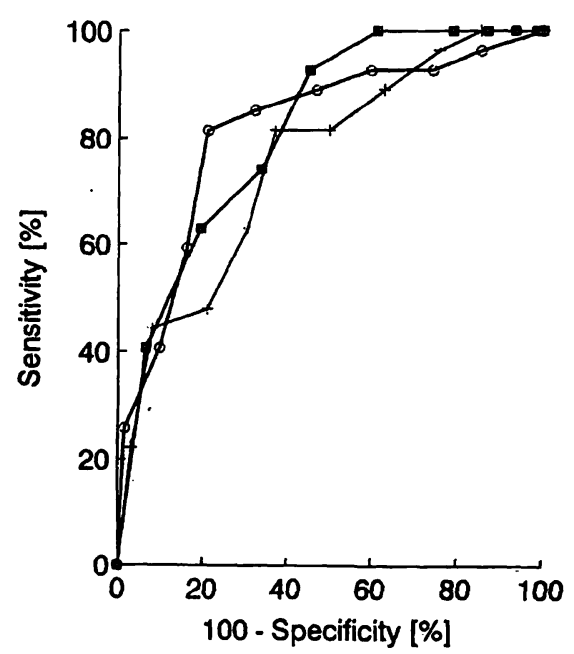

Fig. 3 Receiver-operating characteristic (ROC) analysis of C-terminal propeptide concentrations (indicated by circles), the urinary excretion of deoxypyridinoline (designated by stars) and the combination of both markers (indicated by squares) in patients belonging to groups 2 and 3 (= according to scintigraphic criteria the presence of bone metastases seems to be possible or probable) $(n=27)$ vs patients belonging to groups 0 and 1 (= according to scintigraphic criteria there are no pathological findings or the presence of bone metastases seems to be improbable) $(n=62)$.

Threshold values were fixed corresponding to the 10 th, 20 th, ..., 90th percentile of the distribution of C-terminal propeptide concentrations and deoxypyridinoline excretion in the group of 89 patients examined. For the combination of the two markers an increase of at least one marker above the 10th, 20th, ..., 90th percentile was defined as a positive test result. For these threshold values the diagnostic sensitivities as well as the diagnostic specificities were calculated. 
markers was found to be maximal. For these threshold values the diagnostic sensitivity was $93 \%$; the diagnostic specificity was $55 \%$; the predictive value of a positive test result was $47 \%$; and the predictive value of a negative test result was $94 \%$. The prevalence of patients belonging to groups 2 and 3 was $30 \%$.

\section{Discussion}

It has previously been shown in patients with various types of metabolic bone diseases that the serum concentrations of the C-terminal propeptide correlate with histomorphometric variables of bone formation (2). Both in cancer patients (6) as well as in patients with metabolic bone diseases (2) a correlation of the C-terminal propeptide values with alkaline phosphatase activities was found.

For the interpretation of $\mathrm{C}$-terminal propeptide data it has to be taken into account that a disturbed liver function may yield high serum concentrations probably due to the involvement of liver endothelial cells in the metabolic clearance of this molecule (2). In the present study a major influence of liver function upon C-terminal propeptide values can be excluded because no statistically significant changes of $\gamma$-glutamyl transferase activity concentrations were found between the patient groups examined.

The reference interval for C-terminal propeptide serum concentrations established by us essentially corresponds to that previously described for a radioimmunoassay method (1).

Our results show a high discriminating power of bone alkaline phosphatase values for differentiating between patients with and those without bone metastases, in contrast to the results of van Hoff et al. (10) as well as Stieber et al. (11) who found no such statistically significant difference. This difference may be due to the different localization of the primary tumours as well as due to the different character of the bone lesions (osteoblastic, osteolytic and mixed, respectively). Burlina et al. (12) reported that the determination of bone alkaline phosphatase using wheat-germ lectin precipitation is more specific than total alkaline phosphatase in the identification of bone metastases whereas Cooper et al. (13) showed that bone alkaline phosphatase mass concentrations (as determined immuno-radiometrically) may be elevated in patients with bone metastases while total alkaline phosphatase activities remain in the normal range. In the present study $Z$ score analysis revealed that bone alkaline phosphatase has a higher discriminating power than total alkaline phosphatase with respect to differentiating between patients with and those without bone me- tastases. This corresponds to previous findings of Garnero \& Delmas (14).

Osteocalcin, which is another marker of bone formation, has also been found to be elevated in patients with bone metastases $(15,16)$. Interestingly, a lack of correlation has been shown in these patients between osteocalcin levels and bone alkaline phosphatase values (12). However, two drawbacks of this measurable quantity have to be taken into account when comparing the values with those of bone alkaline phosphatase concentrations:

(a) Decreased renal function may cause increased values of this analyte due to its low relative molecular mass (17).

(b) Osteocalcin concentrations are characterized by a marked diurnal rhythm (18).

To our knowledge there are no examinations concerning other bone matrix proteins with respect to the diagnosis of bone metastases (e.g., osteonectin or proteoglycans [e.g. by employing the monoclonal antibody 5D4 against keratan sulfate]).

Bone formation and bone resorption (as assessed by the determination of bone collagen turnover) are coupled in the patients examined by us which is in concordance with previous findings in tumour patients (4).

The urinary excretion of calcium did not correlate with that of deoxypyridinoline, corresponding to findings in breast cancer patients undergoing therapy with inhibitors of osteoclast activity (19). This strongly supports the hypothesis that calcium and deoxypyridinoline excretion reflect different facets of bone destruction.

Increased excretion values of deoxypyridinoline in four patients in spite of pathological findings being absent as assessed by bone scintigraphy $(4,5)$ may be explained as follows:

(a) one of these four patients showed primary hyperparathyroidism which causes increased values of deoxypyridinoline (20).

(b) the increase of pyridinium cross-links excretion may reflect occult metastases for which the diagnostic sensitivity of bone scintigraphy is too low.

(c) tumour patients being immobilized may result in increased bone resorption (5).

(d) generalised bone resorption which is mediated by parathyroid hormone-related protein may occur (21) but seems to be rather improbable because all patients examined (apart from one case with primary hyperparathyroidism) were normocalcaemic.

Numerous studies have demonstrated that malignant cells secrete many of the factors known to stimulate the 
proliferation and activity of osteoclasts and to produce osteolysis (e.g., transforming growth factors, prostaglandins, tumour necrosis factors and interleukin- $1 \beta$ that has previously been labelled 'osteoclast-activatingfactor') (22-25). Further, osteoclast activation is a key step in the establishment and growths of all bone metastases (23). However, it must be taken into consideration that all of these substances do act as paracrine factors so that measuring these mediators in blood seems to have minor diagnostic significance for monitoring of bone diseases.

For the interpretation of the data presented here the following aspects have to be taken into account:

(a) Detection of lesions by bone scintigraphy depends upon uptake of radioisotopes into areas of new bone formation whereas this method is not suitable for the sensitive detection of lytic lesions (for review see 1.c. (26)). To further enhance the diagnostic sensitivity bone scan scintigraphy should be supplemented by other techniques (e.g., bone marrow scintigraphy, nuclear magnetic resonance tomography and single photon emission computer tomography). On the other hand suspicious findings must be confirmed by $\mathrm{X}$-ray examinations to enhance the diagnostic specificity.

(b) The tumour patients examined by us are heterogeneous with respect to the localization of the primary tumour as well as staging and grading which will affect the prevalence of bone metastases as well as the character of the metastatic bone lesions (osteoblastic, osteoclastic or mixed).

\section{References}

1. Melkko J, Niemi S, Risteli L, Risteli J. Radioimmunoassay of the carboxyterminal propeptide of human type I procollagen. Clin Chem 1990; 36:1328-32.

2. Erikson EF, Charles P, Melson F, Mosekilde L, Risteli L, Risteli J. Serum markers of type I collagen formation and degradation in metabolic bone disease: correlation with bone morphometry. J Bone Min Res 1993; 8:127-32.

3. Seibel MJ. Hydroxy-Pyridinium „Crosslinks“ im Urin als spezifischer Marker der Knochenresorption bei metabolischen Knochenerkrankungen. Klin Lab 1992; 38:642-3.

4. Paterson CR, Robins SP, Horobin JM, Preece PE, Cuschieri A. Pyridinium crosslinks as markers of bone resorption in patients with breast cancer. Br J Cancer 1991; 64:884-6.

5. Lipton A, Demers L, Daniloff Y, Curley E, Hamilton C, Harvey $\mathrm{H}$, et al. Increased urinary excretion of pyridinium crosslinks in cancer patients. Clin Chem 1993; 39:614-8.

6. Fancini G, Gonnelli S, Petrioli R, Bruni S, Marsili S, Aquino A, Camporeale A, et al. Procollagen type I carboxy-terminal propeptide as a marker of osteoblastic activity. Cancer Epidemiol Biomarkers Prev 1993; 2:125-9.

7. Helger R, Rindfrey H, Hilgenfeldt J. Eine Methode zur direkten Bestimmung des Creatinins im Serum and Urin ohne Enteiweißung nach einer modifizierten Jaffé-Methode. Z Klin Chem Klin Biochem 1974; 12:344-9.
Comparison of patients with and those without bone metastases (as detected by bone scintigraphy) yielded a statistically significant difference of the values of both biochemical markers but there is a substantial overlap of the values; for the urinary excretion of deoxypyridinoline this has already been observed in cancer patients $(4,5)$.

The urinary excretion of hydroxyproline has been proposed as an index of bone resorption for the diagnosis (27) and follow-up (28) of patients with malignant tumours. However, several drawbacks limit the clinical usefulness of this quantity for assessment of bone resorption:

(a) hydroxyproline is not exclusively derived from the bone;

(b) hepatic metabolism may alter urinary excretion values;

(c) the urinary excretion depends both upon dietary uptake as well as upon the degradation of newly synthesized collagen (29).

In patients with prostate cancer it has already been shown that serial measurements of the urinary excretion of pyridinium cross-links are suitable for monitoring of clinical progression (29); the same applies to the determination of bone alkaline phosphatase activity in patients with breast cancer (11). Moreover, in patients with tumour-induced osteolysis the urinary excretion of pyridinium cross-links may be a useful quantity for monitoring therapy with agents inhibiting osteoclast activity (e. g., bisphosphonates) (19).

8. Bergmeyer HU, Büttner H, Hillmann G, Kreutz FH, Lang H, Laue D, et al. Empfehlungen der Deutschen Gesellschaft für Klinische Chemie. Standardisierung von Methoden zur Bestimmung von Enzymaktivitäten in biologischen Flüssigkeiten. Experimentelle Begründung der optimierten Standard-Bedingungen. Z Klin Chem Klin Biochem 1972; 10:182-92.

9. Sachs L. Statistische Methoden. Planung und Auswertung. 6th ed. Berlin, Heidelberg, New York, London, Paris, Tokyo: Springer, 1988.

10. Van Hoof VO, van Oosterom AT, Lepoutre LG, de Broe ME. Alkaline phosphatase isoenzyme patterns in malignant disease. Clin Chem 1992; 38:2546-51.

11. Stieber P, Nagel D, Ritzke C, Rössler N, Kirsch CM, Eiermann W, et al. Significance of bone alkaline phosphatase, CA 15-3 and CEA in the detection of bone metastases during followup of patients suffering from breast carcinoma. Eur J Clin Chem Clin Biochem 1992; 30:809-14.

12. Burlina A, Rubin D, Secchiero S, Sciacovelli L, Zaninotto M, Plebani M. Monitoring skeletal cancer metastases with the bone isoenzyme of tissue unspecific alkaline phosphatase. Clin Chim Acta 1994; 226:151-8.

13. Cooper EH, Forbes MA, Hancock AK, Parker D, Laurence V. Serum bone alkaline phosphatase and CA 549 in breast cancer with bone metastases. Biomed Pharmacother 1992; 46:31-6. 
14. Garnero P, Delmas PD. Assessment of the serum levels of bone alkaline phosphatase with a new immunoradiometric assay in patients with metabolic bone disease. J Clin Endocrinol Metab 1993; 77:1046-53.

15. Slovik DM, Gundberg CM, Neer RM, Lian JB. Clinical evaluation of bone turnover by serum osteocalcin measurements in a hospital setting. J Clin Endocrinol Metab 1984; 59:228-30.

16. Stracke H, Schatz C, Pralle H, Ullmann J, Schatz H. Osteocalcin, ein Marker bei Erkrankungen mit erhöhtem Knochenumsatz. Dtsch Med Wochenschr 1985; 110:1442-6.

17. Schmidt $H$, Stracke $H$, Schatz $H$, Scheuermann EH, Fassbinder W, Schoeppe W. Osteocalcin serum levels in patients following renal transplantation. Klin Wochenschr 1989; 67:297-303.

18. Van Straalen JP, Sanders E, Prummel MF, Sanders GTB. Bone-alkaline phosphatase as indicator of bone formation. Clin Chim Acta 1991; 201:27-34.

19. Coleman RE, Houston S, James I, Rodger A, Rubens RD, Leonhard RCF, et al. Preliminary results of the use of urinary excretion of pyridinium cross-links for monitoring metastatic bone disease. Br J Cancer 1992; 65:766-8.

20. Seibel MJ, Gartenberg F, Silverberg SJ, Ratcliffe A, Robins SP, Bilezikian JP. Urinary hydroxypyridinium cross-links of collagen in primary hyperparathyroidism. J Clin Endocrinol Metab 1992; 74:481-6.

21. Burtis WJ. Parathyroid hormone-related protein: structure, function, and measurement [review]. Clin Chem 1992; 38:2171-83.

22. Lorenzo JA. The role of cytokines in the regulation of local bone resorption [review]. Crit Rev Immunol 1991; 11:195213.

23. Coleman RE, Purohit OP. Osteoclast inhibition for the treatment of bone metastases [review]. Cancer Treat Rev 1993; 19:79-103.
24. Lorenzo JA, Sousa SL, Alander C, Raisz LG, Dinarello CA. Comparison of the bone-resorbing activity in the supernatants from phytohemagglutinin-stimulated human peripheral blood mononuclear cells with that of cytokines through the use of an antiserum to interleukin 1. Endocrinology 1987; 121:116470.

25. Dewhirst FE, Stashenko PP, Mole JE, Tsurumachi T. Purification and partial sequence of human osteoclast-activating factor: identity with interleukin 1 beta. J Immunol 1985; 135:2562-8.

26. Linden A, Schicha $H$. Skelettmetastasen maligner Tumoren diagnostische Strategien unter Berücksichtigung neuer Untersuchungsverfahren. Med Klin 1992; 87:39-41.

27. Gielen F, Dequeker J, Drochmans A, Wildiers J, Merlevede M. Relevance of hydroxyproline excretion to bone metastasis in breast cancer. Br J Cancer 1976; 34:279-85.

28. Hopkins SC, Nissenkorn I, Palmieri GMA, Ikard M, Moinud$\operatorname{din} \mathrm{M}$, Soloway MS. Serial spot hydroxyproline/creatinine ratios in metastatic prostatic cancer. J Urol 1983; 129:319-23.

29. Miyamoto KK, McSherry SA, Robins SP, Besterman JM, Mohler JL. Collagen cross-links metabolites in urine as markers of bone metastases in prostatic cancer. J Urol 1994; 151:909-13.

Dr. med. Wolfgang Withold

Institute for Clinical Chemistry and

Laboratory Diagnostics

Heinrich-Heine-University of Düsseldorf

Moorenstraße 5

D-40225 Düsseldorf

Germany 
.

, 